\title{
EDITORIAL
}

\section{In This Issue: Sometimes More is Less}

\author{
Kurt C. Stange, $M D, P b D$, Editor
}

Ann Fam Med 2018;16:190-191. https://doi.org/10.1370/afm.2253.

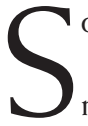

ometimes more is less.

In this issue, a study by Peterson shows that new family physicians who provide more through a broader scope of practice-inpatient, obstetrical, or home visit care- have less burnout than those with a narrower scope of practice. ${ }^{1}$ Perhaps a part of the solution to the Quadruple $\mathrm{Aim}^{2}$ of better population health, patient experience, sustainable cost, and a joyful workforce free of burnout is to train and support family physicians in full scope of practice.

An essay by Card provides a related perspective by distinguishing between unavoidable suffering that is inherent in the physician's role of service and system failures that are a preventable cause of burnout. Card argues that resilience training may be appropriate and helpful in managing unavoidable suffering, but unhelpful if it only masks and allows harmful systemic practices to continue. ${ }^{3}$

The theme of more is less continues with Applequist et al's update of a landmark study by Frosch et al ${ }^{4}$ of direct-to-consumer television ads for prescription drugs. They find that, compared with the previous study, ads focus more on selling drugs and less on the conditions being treated or on alternatives to drug treatment. ${ }^{5}$ This new research supports prior concerns about the effect of direct-to-consumer ads on public health and health care. ${ }^{6,7}$

More social complexity in patients' lives is associated with less positive outcomes in a study of a 626,264 primary care patients in Manitoba, Canada. More than one-half of patients have a least 1 social complexity and $4 \%$ have 5 or more social challenges. ${ }^{8}$

More emphasis on specific aspects of care transitions, identified from the perspectives of patients and family caregivers in 6 health networks across the United States, has the potential to lead to care that is less transactional and unsafe. Aspects of care transitions linked to desired outcomes include providing actionable information, collaborative discharge planning, empathic communication, anticipating patients' needs at home, and providing uninterrupted care while minimizing handoffs. ${ }^{9}$

Further insights into successful care management are provided in a mixed methods study of patients with chronic disease and complex care needs who are frequent users of primary care. The clinical trial portion of the study evaluates an individualized, nursedelivered care coordination and self-management support intervention. The intervention results in less psychological distress but no difference in patient activation. Qualitative analyses suggest a benefit in sense of security and self-management abilities. ${ }^{10}$

In a study of a policy change that provides free access to daytime and out-of-hours general practice services for young children in the Republic of Ireland, O'Callaghan et al find that more leads to more-a $25 \%$ increase in utilization. ${ }^{11}$

A prospective study assesses the predictive value of the Visual Association Test for development of dementia. The authors find added value to the Mini-Mental State Examination. ${ }^{2}$

A literature synthesis by Hartzler and colleagues provides a helpful understanding of 12 functions and 3 roles of community health workers in primary care. ${ }^{13}$

A special report describes experience with the Council of Academic Family Medicine Educational Research Alliance (CERA) infrastructure that allows individual investigators to add questions to omnibus surveys of family medicine educational leaders. The many expediencies and supports in the CERA process have allowed over 115 research teams to conduct studies in an expedited and efficient way. ${ }^{14}$

A theory analysis by Norful and colleagues presents a model of patient co-management between nurse practitioners and physicians. They posit that successful co-management involves effective communication, mutual respect and trust, clinical alignment, and a shared philosophy of care. ${ }^{15}$

Two essays in this issue are personal and compelling. Daaleman explores deserts of mind and soul, and points out a pathway to hope. ${ }^{16}$ Romano confronts his white privilege as a physician in training. ${ }^{17} \mathrm{He}$ and editorialist Joseph Hobbs explore the personal implications and larger systemic manifestations of implicit or unconscious bias. ${ }^{18}$

The Annals feature on Innovations in Primary Care in this issue includes a novel approach to improving patient relationships and treatment adherence by 
gathering and using patient-reported profile information that includes: identity descriptors, health beliefs, personality type, learning style, communication preferences, and health literacy level. ${ }^{19}$

We welcome you to join the online discussion for these and previously published articles at http://www. AnnFamMed.org.

\section{References}

1. Weidner AKH, Phillips RL, Fang B, Peterson LE. Burnout and scope of practice in new family physicians. Ann Fam Med. 2018;16(3): 200-205.

2. Bodenheimer T, Sinsky C. From triple to quadruple aim: care of the patient requires care of the provider. Ann Fam Med. 2014;12(6): 573-576.

3. Card AJ. Physician burnout: resilience training is only part of the solution. Ann Fam Med. 2018;16(3):267-270.

4. Frosch DL, Krueger PM, Hornik RC, Cronholm PF, Barg FK. Creating demand for prescription drugs: a content analysis of television direct-to-consumer advertising. Ann Fam Med. 2007;5(1):6-13.

5. Applequist J, Ball JG. An updated analysis of direct-to-consumer television advertisements for prescription drugs. Ann Fam Med. 2018;16(3):211-216.

6. Stange KC. On TRACK: Intended and unintended consequences of direct-to-consumer drug marketing. Ann Am Fam. 2007;5(2): 175-178.

7. Stange KC. Time to ban direct-to-consumer prescription drug marketing. Ann Fam Med. 2007;5(2):101-104.

8. Katz A, Chateau D, Enns J, et al. Association of the social determinants of health with quality of primary care. Ann Fam Med. 2018;16(3):217-224.
9. Mitchell SE, Laurens V, Weigel G, et al. Care transitions from patient and caregiver perspectives. Ann Fam Med. 2018;16(3):225-231.

10. Hudon C, Chouinard M-C, Dubois M-F, et al. Case management in primary care for frequent users of health care services: a mixed methods study. Ann Fam Med. 2018;16(3):232-239.

11. O'Callaghan ME, Zgaga L, O'Ciardha D, O'Dowd T. Free children's visits and general practice attendance. Ann Fam Med. 2018;16(3): 246-249.

12. Jongstra S, van Gool WA, Moll van Charante EP, et al. Improving prediction of dementia in primary care. Ann Fam Med. 2018;16(3): 206-210.

13. Hartzler AL, Tuzzio L, Hsu C, Wagner EH. Roles and functions of community health workers in primary care. Ann Fam Med. 2018; 16(3):240-245.

14. Seehusen DA, Mainous III AG, Chessman AW. Creating a centralized infrastructure to facilitate medical education research. Ann Fam Med. 2018;16(3):257-260.

15. Norful AA, de Jacq K, Carlino R, Poghosyan L. Nurse practitionerphysician comanagement: a theoretical model to alleviate primary care strain. Ann Fam Med. 2018;16(3):250-256.

16. Daaleman TP. The mid-career demon. Ann Fam Med. 2018;16(3): 264-266.

17. Romano MJ. White privilege in a white coat: how racism shaped my medical education. Ann Fam Med. 2018;16(3):261-263.

18. Hobbs J. White privilege in health care: following recognition with action. Ann Fam Med. 2018;16(3):197-198.

19. Barba C, Hammond S, Hammond RS. The patient profile: improving treatment adherence. Ann Fam Med. 2018;16(3):271-271.

\section{Correction}

Ann Fam Med 2018;16:191. https://doi.org/10.1370/afm.2242.

In the Reflections essay, "The Day I Died" (Stausmire JM, Greenbaum MG, Morelli-Greenbaum M. The day I died. Ann Fam Med. 2018;16(1):77-79) in the January/February issue of Annals of Family Medicine, the sentence, "The cardiac catheterization demonstrated I had a $100 \%$ blockage of the left main anterior descending artery as well as 4 other significant blockages" should have read, "The cardiac catheterization demonstrated I had a $100 \%$ blockage of the left anterior descending artery branching off the left main artery, as well as 4 other significant blockages." The author regrets the error. 